In conclusion, this report shows the feasibility of TAVI for the treatment of structural deterioration of a stentless aortic bioprosthesis, suggesting that TAVI might be further considered for the treatment of this highly challenging subset of patients. However, the efficacy and safety of this strategy should be determined in prospective studies with a large number of patients and long-term follow-up.

We thank Drs Sebastien Bergeron, Jacques Villeneuve, Robert DeLarochellière, and Rodrigo Bagur from the Laval Hospital and Mark Dedahstian, MS, from Edwards Lifesciences, Inc, for their help during the procedure and the careful review of the manuscript. We also thank Marie-Annick Clavel, MSc, for technical assistance.

\section{References}

1. Borger MA, Prasongsukarn K, Armstrong S, Feindel CM, David TE. Stentless aortic valve reoperations: a surgical challenge. Ann Thorac Surg. 2007;84:737-43.

2. Rodés-Cabau J, Dumont E, DelaRochellière R, Doyle D, Lemieux J, Bergeron S, et al. Feasibility and initial results of percutaneous aortic valve implantation including selection of the transfemoral or transapical approach in patients with severe aortic stenosis. Am J Cardiol. 2008;102:1240-6.

3. Ng ACT, van der Kley F, Delgado V, Shanks M, van Bommel RJ, de Wegger A, et al. Percutaneous valve-in-valve procedure for severe paravalvular regurgitation in aortic bioprosthesis. JACC Cardiovasc Imaging. 2009;2:522-3.

4. Wenaweser P, Buellesfeld L, Gerckens U, Grube E. Percutaneous aortic valve replacement for severe aortic regurgitation in degenerated bioprosthesis: the first valve in valve procedure using the Corevalve Revalving system. Catheter Cardiovasc Interv. 2007;70:760-4.

5. Dumont E, Lemieux J, Doyle D, Rodés-Cabau J. Feasibility of transapical aortic valve implantation fully guided by transesophageal echocardiography. $J$ Thorac Cardiovasc Surg. 2009 [Epub ahead of print].

\title{
Balloon-guided, tapered, Polyflex stent guidance: An atraumatic technique for successful stent placement through tight, rigid airway stenoses
}

\author{
Moishe Liberman, MD, ${ }^{\mathrm{a}}$ and John C. Wain, MD, ${ }^{\mathrm{b}}$ Montreal, Quebec, Canada, and Boston, Mass
}

Supplemental material is available online.

Benign airway strictures are often effectively treated with sequential dilation. However, when this is not successful, or in cases of frequent stricture recurrence, retrievable stenting can relieve symptoms as well as allow for airway remodeling, resulting in a less stenotic lumen. Anastomotic strictures are often difficult to dilate owing to fibrosis and suture reaction. Reoperation in these cases is often extremely challenging owing to the limited length of airway remaining after the first operation. In these cases, we prefer to use silicone stents after dilation to allow stricture remodeling. The Polyflex

From the Division of Thoracic Surgery, ${ }^{\text {a }}$ Centre Hospitalier de l'Université de Montréal, University of Montreal, Montreal, Quebec, Canada; and the Division of Thoracic Surgery, ${ }^{\mathrm{b}}$ Massachusetts General Hospital, Harvard University, Boston, Mass.

Disclosures: None.

Received for publication May 20, 2009; revisions received Sept 14, 2009; accepted for publication Sept 17, 2009; available ahead of print Jan 18, 2010.

Address for reprints: Moishe Liberman, MD, Department of Thoracic Surgery, The Centre Hospitalier de l'Université de Montréal, 1560 rue Sherbrooke Est 8e CD, Room D-8051, Montreal, Quebec, Canada H2L 4M1 (E-mail: moishe.liberman@ umontreal.ca).

J Thorac Cardiovasc Surg 2010;140:248-9

$0022-5223 / \$ 36.00$

Copyright (c) 2010 by The American Association for Thoracic Surgery

doi:10.1016/j.jtcvs.2009.09.061 self-expanding polyester/silicone airway stent (Boston Scientific, Boston, Mass) works well for these challenging cases because it is completely covered, thin-walled, and does not contain any metallic elements.

The main challenge with the Polyflex stent delivery system is that it must be positioned through the area of stenosis. This proves to be extremely difficult in some strictures owing to the inflexibility of the stenosis and the blunt, rigid, stent insertion system (Figure 1). The stent delivery device is nondeformable in its undeployed state and requires internal stenting to permit atraumatic passage through some strictures. To circumvent this, we insert a pulmonary balloon dilator (CRE pulmonary balloon dilator; Boston Scientific) through the delivery system and then through the stent. The balloon is inflated with the tip protruding from the delivery system by approximately $10 \mathrm{~mm}$ (Figure $2, A$ ). The balloon acts as a tapered tip for the stent delivery system and allows the delivery system to easily traverse the stenosis without traumatizing it. The balloon is guided down to and

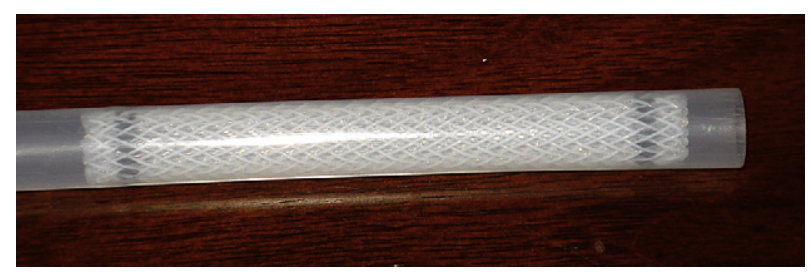

FIGURE 1. The Polyflex stent delivery system. 

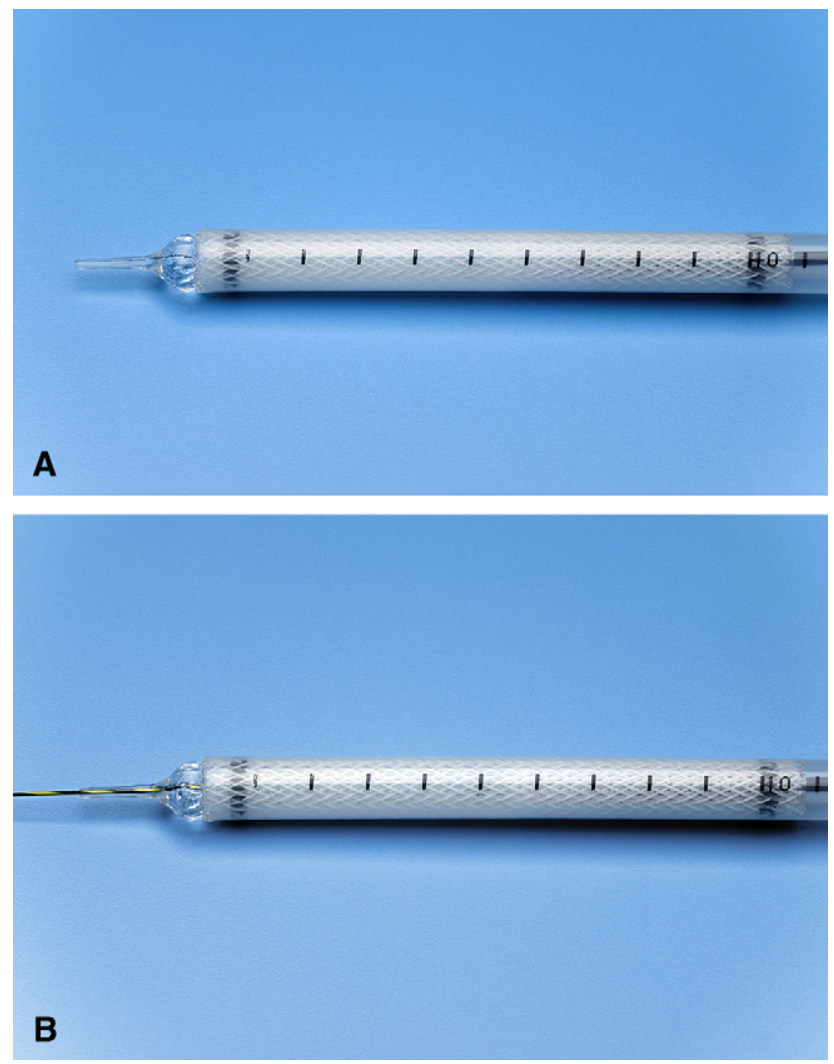

FIGURE 2. A, Pulmonary balloon dilator with the tip protruding from the delivery system by approximately $10 \mathrm{~mm}$. B, The balloon is guided down to and through the stenosis over a guidewire under fluoroscopic guidance.

through the stenosis over a guidewire (Figure 2, B) under fluoroscopic guidance. Once the stent is positioned through the stenosis, the balloon is deflated and removed. The stent is then slowly deployed as the delivery system is withdrawn. This technique has significantly improved the ease and decreased the luminal trauma of Polyflex stent insertion through tight strictures.

\section{CLINICAL SUMMARY}

A 16-year old boy underwent mechanical debridement and iridium wire brachytherapy for an obstructing typical carcinoid tumor in the left main stem bronchus at an outside hospital. He was subsequently referred for surgical resection. The entire left main bronchus and tracheal carina had been injured as a result of the iridium wire therapy. The patient underwent successful left main stem sleeve resection. Over the ensuing year, the patient required serial balloon dilations and debridement for anastomotic stricture.

The patient's anatomy was such that there was insufficient airway for further resection and reconstruction, and the only surgical option was pneumonectomy. The entire remaining left main stem bronchus and carina appeared to be involved in the iridium damage. He had only a 7-mm segment of damaged airway between the carina and the stenosis (Figure E1) and a 6-mm segment between the stenosis and the secondary carina.

We decided to attempt silicone stent insertion to allow airway remodeling. A 12- $\mathrm{mm}$ inner diameter, 20-mm long Polyflex airway stent was selected for insertion. This proved to be very difficult because the stenotic segment did not allow passage of the blunt Polyflex stent delivery system (9-mm diameter) and the blunt end of the delivery system was at risk of traumatizing the already irritated and inflamed airway mucosa. A 12-mm balloon was placed within the stent, and this allowed easy passage through the stenosis (Figure E1) over a guidewire under fluoroscopic guidance (Figure E2).

\section{DISCUSSION}

Although the idea for airway stenting can be traced back as far as the 1800 s, only fairly recently has technology evolved to allow stenting to become a viable and important treatment option to relieve airway obstruction. ${ }^{1,2}$ Stents are available in many varieties. They can be used in the permanent/palliative setting for malignant airway obstruction ${ }^{3}$ or can be used temporarily to allow either healing or treatment of the underlying disease. ${ }^{4}$ Silicone stents work well for nonresectable postoperative anastomotic strictures both in cases of tracheobronchial resection and after lung transplantation. The Polyflex self-expanding silicone airway stent works well for these challenging cases because it is completely covered, thin-walled, and does not contain any metallic elements.

To circumvent the difficulties in delivering the device into the area of stenosis, we have developed a simple technique that adapts the distal end of the delivery device using a bronchial dilating balloon. This technique has worked well for difficult cases.

Insertion of the balloon-guided, tapered Polyflex selfexpanding silicone airway stent by the modified technique described here is an atraumatic method for successful stent placement through tight, rigid airway stenoses.

\section{References}

1. Dumon JF. A dedicated tracheobronchial stent. Chest. 1990;97:328-32.

2. Bolliger CT, Probst R, Tschopp K, Soler M, Perrouchoud AP. Silicone stents in the management of inoperable tracheobronchial stenosis: indications and limitations. Chest. 1993;104:1653-9.

3. Ernst A, Feller-Kopman D, Becker HD, Mehta AC. Central airway obstruction. Am J Respir Crit Care Med. 2004;169:1278-97.

4. Kim JH, Shin JH, Song HY, Shim TS, Yoon CJ, Ko GY. Benign tracheobronchial strictures: long-term results and factors affecting airway patency after temporary stent placement. AJR Am J Roentgenol. 2007;188:1033-8. 


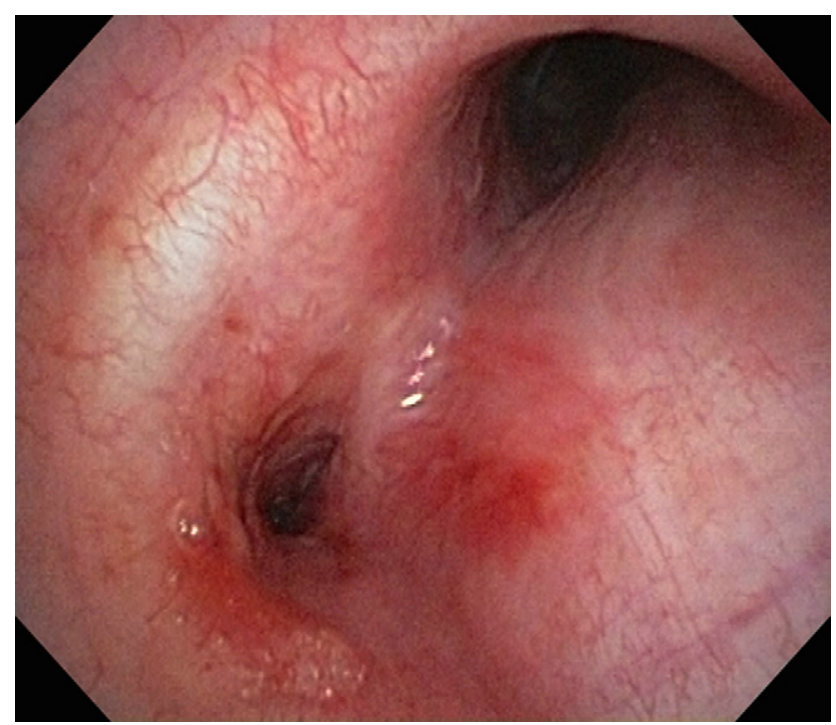

FIGURE E1. The entire remaining left main stem bronchus and carina appeared to be involved in the iridium damage and he only had a 7- $\mathrm{mm}$ segment of damaged airway between the carina and the stenosis.

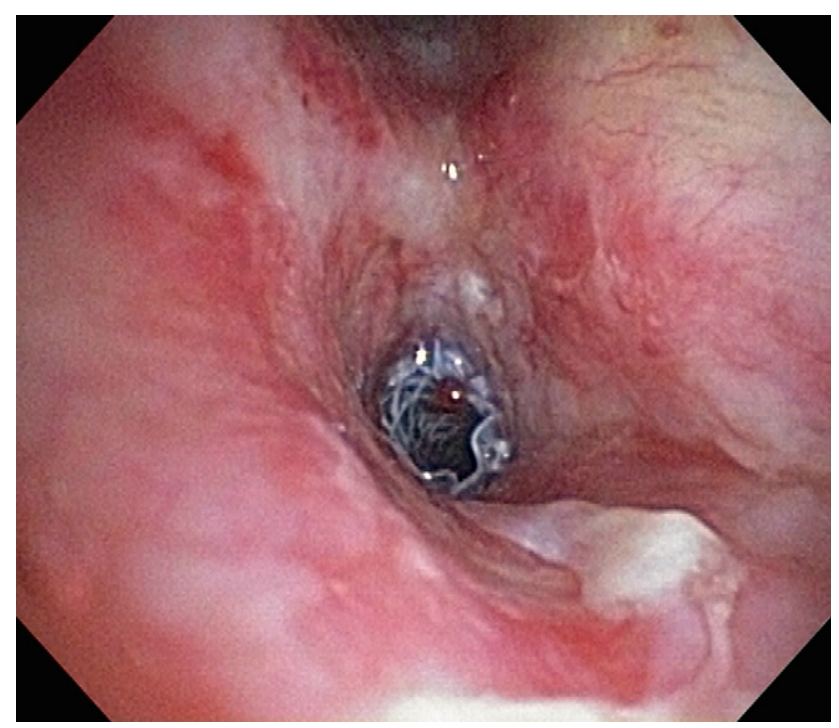

FIGURE E2. A 12-mm balloon was placed within the stent and this allowed easy passage through the stenosis over a guidewire under fluoroscopic guidance. 